\title{
Comparison of Adiponectin Levels During the Menstrual Cycle Between Normal Weight and Overweight/Obese Young Females
}

\author{
A. M. SALEM ${ }^{1}$, R. LATIF ${ }^{1}$, N. RAFIQUE ${ }^{1}$ \\ ${ }^{1}$ Department of Physiology, College of Medicine, Imam Abdulrahman Bin Faisal University, \\ Dammam, Saudi Arabia
}

Received April 29, 2019

Accepted August 2, 2019

Epub Ahead of Print October 25, 2019

\section{Summary}

To compare serum adiponectin changes across the menstrual cycle between normal weight and overweight/obese young women and its correlation with serum estradiol. Young women $(n=56)$ with regular menstrual cycle had been grouped according to their BMI into normal weight group $(n=26)$ and overweight /obese group $(n=30)$. Blood samples were drawn during early follicular (FP), pre-ovulatory (OP) and luteal phases (LP) of menstrual cycle for serum adiponectin and estradiol levels determination using enzyme-linked immunosorbent assay. Adiponectin serum level showed a significant decreasing pattern across the phases of menstrual cycle in normal weight group. This pattern was absent in the overweight/obese group. In addition, serum adiponectin was lower in overweight/obese group compared to normal weight subjects through all phases of menstrual cycle. No correlation was found between adiponectin and estradiol levels in both groups. A significant variation of serum adiponectin level was detected across the menstrual cycle in females with normal weight. In comparison, overweight/obese group showed a relatively stable adiponectin level throughout the cycle. This lack of adiponectin variation might be added to the complex mechanisms lies behind obesity-related female infertility.

\section{Key words}

Adipokines • Adiponectin • Menstrual Cycle • Estradiol • BMI

\section{Corresponding author}

A. M. Salem, Department of Physiology, College of Medicine, Imam Abdulrahman Bin Faisal University, Dammam, Kingdome of Saudi Arabia. E mail: ayadsalem@iau.edu.sa

\section{Introduction}

Obesity has been considered a new epidemic in the world. A dramatic increase in obesity prevalence was observed over the past 30 years. According to WHO, more than half a billion adults worldwide are complaining of obesity (Nguyen and El-Serag 2010). A high obesity prevalence of $28.7 \%$ was also recorded in Saudi Arabia with more prevalence among women than men (33.5 \% vs. $24.1 \%$ ) (Memish et al. 2014). It is well documented that obesity could reduce fertility in humans, obese females are at higher risk of subfertility and less likely to conceive than lean women (Best and Bhattacharya 2015). Recently, reproductive function has been found to be closely related to the energy homeostasis (Michalakis et al. 2013), there are increasing pieces of evidence for the role of adipokines in the link between reproductive function and nutritional status (Comninos et al. 2014).

Adiponectin, a 244 amino acids protein was discovered in 1995 (Scherer et al. 1995), it is the most abundant circulating adipocytokines produced exclusively in white adipose tissue (Maeda et al. 1996) with a higher levels in females than in males (Bottner et al. 2004). Three receptors for adiponectin AdipoR1, AdipoR2 and t-cadherin are found in the peripheral tissues (Combs and Marliss 2014). Contrary to other adipose tissue hormones, adiponectin circulating levels are lower in obese individuals and increases with weight reduction (Balsan et al. 2015). The anti-diabetic effect of adiponectin in improving insulin sensitivity in liver and skeletal muscle as well as the regulation of energy 
homeostasis is well known. During the last 20 years, antiinflammatory, anti-atherogenic and anti-apoptotic effects were further demonstrated (Michalakis et al. 2013). Recently, adiponectin has been linked with many obesityrelated disorders like metabolic syndrome, cardiovascular diseases, and hypertension (Blüher and Mantzoros 2015).

Both, expression of adiponectin receptors in the hypothalamic-pituitary-gonadal axis, as well as the sexual dimorphism of adiponectin concentration reflects a possible modulatory effect of this adipocytokine on the reproductive endocrine axis (Kawwass et al. 2015). Furthermore, an interrelationship between adiponectin and sex hormones have been elucidated by many studies, adiponectin levels were found to be higher during estrogen depletion at human menopause, than in premenopause period (Jurimae and Jurimae 2007a, Tamakoshi et al. 2007). Circulating adiponectin levels are also elevated when the GnRH secretion disturbed such in hypogonadotropic hypogonadism (Lanfranco et al. 2004). However, it seems that adiponectin predominately play an inhibitory action on the hypothalamus and pituitary, as it decreases GnRH secretion from hypothalamic neurons (Wen et al. 2008, Cheng et al. 2011) and suppresses the LH secretion in rodents pituitary explants ( $\mathrm{Lu}$ et al. 2008). In contrast, the effect of adiponectin on the gonads is differed according to the sex, while it follows the overall inhibitory role in the male tests by decreasing testosterone secretion (Caminos et al. 2008), it plays a permissive effect on rodent ovaries by increase estrogen and progesterone secretion (Chabrolle et al. 2009).

Nonetheless, these accumulated shreds of evidence suggested a regulatory role of adiponectin in the endocrine system of reproduction, its exact role in female reproduction still debatable. Published results from previous studies are conflicting regarding adiponectin level during menstrual cycle and its relationship to the sex hormone, some studies failed to show any significant variation during the normal menstrual phases in humans or mice (Kleiblova et al. 2006, Asimakopoulos et al. 2009, Dafopoulos et al. 2009). On another hand, Sramkova et al. (2015) reported a significant higher level of adiponectin during menstrual cycle.

These conflicting finding presenting earlier deliver a need for further investigation about the role of adiponectin in the field of female's reproductive endocrinology. Only a few studies have been investigated the variation of adiponectin during menstrual cycle in human. In addition, very limited studies were evaluating the difference in adiponectin levels between females with normal BMI and those with BMI above normal during different phases of the menstrual cycle. Hence, the primary objective of the current study is to compare the serum level of adiponectin during different phases of menstrual cycle between normal and overweight/ obese women and to correlate its level with the level of estrogen. In addition, we investigated the pattern of adiponectin variation across the phases of menstrual cycle in the whole cohort as secondary outcome.

\section{Methods}

This prospective cohort study was conducted at Imam Abdulrahman Bin Faisal University. Fifty-six female students (18-25 years) with a regular menstrual period were recruited by convenience sampling. Pregnant females, breastfeeding, with irregular menstrual cycle or were on oral contraceptives have been excluded. Ethical approval was obtained from the Institutional Review Board (2014-01-173). Written consent was obtained from every subject.

Subjects were classified according to their body mass index into two groups: normal weight group included 26 females with body mass index between 18.5-24.99 and overweight/obese group (30 females) with body mass index $\geq 25$. BMI was calculated as $\left(\mathrm{kg} / \mathrm{m}^{2}\right)$, weight and height were measured using Sicca digital scale and stadiometer respectively, waist and hip circumferences were measured with a non-stretchable plastic tape. The subjects were briefed about the project and they were instructed about how to make a basal body temperature chart.

The study was run over one menstrual cycle for each subject. Blood samples were collected during the menstrual cycle as follows: during the first 3-5 days of menstrual cycle (Early Follicular Phase), from days 11 to 16 before the onset of the next menstrual cycle (Pre-ovulatory Phase), and the third one at 3-5 days before onset of next menstrual cycle (Luteal Phase). The basal body temperature chart and serum estradiol level fluctuation were used for further verification of cycle phases (Latif and Rafique 2015).

To minimize the effects of diet and circadian rhythm on adiponectin and estrogen levels, blood samples were collected after an overnight fast between 8-10 AM. Five $\mathrm{ml}$ of blood were collected in and left to clot, samples were centrifuged, and the collected serum was stored at $-80{ }^{\circ} \mathrm{C}$ for future analysis. All samples from each subject's menstrual cycle were run together in one 
kit to control for inter-assay differences. Adiponectin was measured by manual sandwich enzyme-linked immunosorbent assay method using Adiponectin (B-Bridge International, Inc) kits. The inter-assay and intraassay coefficient of variation (CV) was $7.3 \%$ and $3.6 \%$ respectively. Serum estradiol level was measured using estradiol Eliza kits (Sigma Aldrich), with a CV less than $10 \%$.

Data were expressed as arithmetic means \pm standard deviation, one-way repeated measure ANOVA with post hoc multiple comparisons were performed to compare each variable within the same group at different menstrual phases. The differences between normal weight and overweight/obese groups were analyzed using unpaired t-test, a correlation between adiponectin and estradiol levels was tested using Pearson correlation coefficients. Statistical software (SPSS-version 20) was used and a $\mathrm{P}$ value of $<0.05$ was considered significant.

\section{Results}

The participants' characteristics in the two study groups are listed in (Table 1). The mean duration of the menstrual cycle was $29 \pm 1 \quad($ mean \pm SD) days (range $=27-31$ days).

Adiponectin serum level showed a decreasing pattern across the phases of menstrual cycle in normal weight group, the higher level during follicular phase $(8.23 \pm 4.66 \mu \mathrm{g} / \mathrm{dl})$ was declined through ovulatory phase $(7.10 \pm 3.25 \mu / \mathrm{ml})$ to reach its lowest level (6.71 $\pm 3.09 \mu / \mathrm{ml}, \mathrm{p}=0.049)$ at luteal phase (Table 2). This pattern of adiponectin variation was absent in overweight/obese group as well as when we combined

Table 1. Baseline anthropometric measurements of the participants.

\begin{tabular}{|c|c|c|c|}
\hline $\begin{array}{l}\text { Variables } \\
(\text { mean } \pm \text { SD })\end{array}$ & $\begin{array}{l}\text { Normal weight group } \\
\qquad(n=26)\end{array}$ & $\begin{array}{l}\text { Overweight/obese group } \\
\qquad(n=30)\end{array}$ & $P$ value \\
\hline Weight (kg) & $52.60 \pm 6.46$ & $78.27 \pm 12.16$ & $<0.001 *$ \\
\hline Height $(\mathrm{cm})$ & $154.60 \pm 5.57$ & $157.66 \pm 5.84$ & 0.051 \\
\hline$B M I\left(k g / m^{2}\right)$ & $21.97 \pm 1.89$ & $31.39 \pm 3.57$ & $<0.001^{*}$ \\
\hline Waist circumference (cm) & $75.69 \pm 5.88$ & $87.25 \pm 14.70$ & $<0.001 *$ \\
\hline Hip circumference $(\mathrm{cm})$ & $98.58 \pm 7.05$ & $111.43 \pm 16.53$ & $<0.001^{*}$ \\
\hline Waist / hip $(W / H)$ ratio & $0.77 \pm 0.06$ & $0.78 \pm 0.07$ & 0.711 \\
\hline
\end{tabular}

*Significant level

Table 2. Comparisons of serum adiponectin and estrdiol levels within and between groups at different phases of the menstrual cycle.

\begin{tabular}{|c|c|c|c|c|}
\hline $\begin{array}{l}\text { Hormones } \\
(\text { mean } \pm \text { SD) }\end{array}$ & & Normal weight group & $\begin{array}{l}\text { Overweight - } \\
\text { obese group }\end{array}$ & $\begin{array}{c}\text { P value (between } \\
\text { groups) }\end{array}$ \\
\hline Adiponectin & Follicular phase (FP) & $8.23 \pm 4.66$ & $5.30 \pm 2.96$ & $0.02 *$ \\
\hline \multirow[t]{3}{*}{$(\mu g / m l)$} & Preovulatory phase (PO) & $7.10 \pm 3.25$ & $5.24 \pm 3.11$ & $0.03 *$ \\
\hline & Luteal phase (LP) & $6.71 \pm 3.09$ & $5.87 \pm 5.13$ & 0.07 \\
\hline & P value (within group) & $0.049^{*}$ & 0.80 & \\
\hline Estradiol & Follicular phase (FP) & $48.94 \pm 23.18$ & $41.04 \pm 21.69$ & 0.209 \\
\hline \multirow[t]{3}{*}{$(p g / m l)$} & Preovulatory phase (PO) & $78.42 \pm 45.02$ & $74.79 \pm 58.64$ & 0.806 \\
\hline & Luteal phase (LP) & $67.83 \pm 41.19$ & $67.63 \pm 32.51$ & 0.985 \\
\hline & P value (within group) & $0.045^{*}$ & $0.017^{*}$ & \\
\hline
\end{tabular}

*Significant level 
both groups together (Table 2 and 3). In addition, between-groups comparison showed lower serum adiponectin in overweight/obese subjects compared to normal-weight subjects during follicular (5.30 \pm 2.96 vs. $8.23 \pm 4.66 \mu / \mathrm{ml}, \mathrm{p}=0.02$ respectively) and preovulatory phases $\quad(5.24 \pm 3.11 \quad$ vs. $7.10 \pm 3.25 \mu / \mathrm{ml}, \quad \mathrm{p}=0.03$ respectively) (Table 2). In contrast, estradiol was significantly increased from early follicular to pre- ovulatory phase with insignificant decrease from preovulatory to the luteal phase in both study groups separately as well as in the whole cohort (Table 2, 3). No significant difference was found in serum estradiol level between normal weight and overweight /obese groups across all phases of menstrual cycle (Table 2).

No significant correlation was found between adiponectin and estradiol level in both groups (Table 4).

Table 3. Serum adiponectin and estradiol levels in different phases of the menstrual cycle in all subjects of the study.

\begin{tabular}{lcccc}
\hline \multirow{2}{*}{$\begin{array}{l}\text { Hormones } \\
\text { (mean } \pm \text { SD) }\end{array}$} & \multicolumn{3}{c}{ Phases of menstrual cycle } & \multirow{2}{*}{ P value } \\
\cline { 2 - 4 } & $\begin{array}{c}\text { Follicular phase } \\
(\text { FP) }\end{array}$ & $\begin{array}{c}\text { Pre-Ovulation } \\
(\mathbf{O P})\end{array}$ & $\begin{array}{c}\text { Luteal phase } \\
\text { (LP) }\end{array}$ & \\
\hline Adiponectin $(\mu \mathrm{g} / \mathrm{ml})$ & $6.66 \pm 4.08$ & $6.10 \pm 3.28$ & $6.26 \pm 4.29$ & 0.51 \\
Estradiol $(\mathrm{pg} / \mathrm{ml})$ & $44.58 \pm 22.62$ & $77.36 \pm 52.44$ & $67.55 \pm 36.75$ & $0.001 *$ \\
\hline
\end{tabular}

* Significant level for FP vs. both OP \& LP using repeated measure ANOVA

Table 4. Correlation between serum adiponectin and estradiol at different phases of the menstrual cycle.

\begin{tabular}{|c|c|c|c|c|c|c|c|}
\hline \multirow[t]{2}{*}{ Parameters } & & \multicolumn{3}{|c|}{ Normal weight group } & \multicolumn{3}{|c|}{ Overweight/obese group } \\
\hline & & FP & OP & $\mathbf{L P}$ & $\mathbf{F P}$ & OP & $\mathbf{L P}$ \\
\hline \multirow{2}{*}{$\begin{array}{l}\text { Adiponectin vs. } \\
\text { estradiol }\end{array}$} & Pearson correlation & 0.008 & 0.07 & -0.24 & 0.30 & 0.19 & 0.09 \\
\hline & P value (two tailed) & 0.96 & 0.71 & 0.22 & 0.14 & 0.35 & 0.66 \\
\hline
\end{tabular}

$\mathrm{FP}=$ follicular phase, $\mathrm{OP}=$ pre-ovulatory phase, $\mathrm{LP}=$ luteal phase

\section{Discussion}

The current study showed a significant decreasing pattern in adiponectin levels across the menstrual cycle of the normal weight group. This pattern was absent in overweigh/obese group and no correlation with estradiol levels was found in both groups.

Previous studies on the adiponectin variations during menstrual phases in human are limited and showed inconsistent results. Our findings are in accordance with a recent study investigating the level of adipokines and some steroid during the menstrual cycle of normal weight young women, adiponectin was found to be significantly higher during the middle of the cycle compared to late luteal phase (Sramkova et al. 2015).

However, several studies showed stable adiponectin level across menstrual cycle, two previous small studies of normal weight females showed no significant variation in adiponectin levels across the menstrual cycle despite the characteristic dramatic changes of estrogen level (Kleiblova et al. 2006, Asimakopoulos et al. 2009). Serum adiponectin levels were also found to be stable in young healthy women (Saxena et al. 2012) as well as in pre-menopausal women with regular cycles, whether the cycles were ovulatory or non-ovulatory (Hall et al. 2009, Rouen et al. 2010). It is important to note that, large variation in adiponectin levels were reported between individuals as well as many confounders such as BMI, age, physical activity, and food consumption, and the presence of various adiponectin isoforms in the blood could explain this variation. However, our study confirms the variation of adiponectin during menstrual cycle in normal weight young women. Although in the current study no correlation between estrogen and adiponectin had been detected, still the declined adiponectin level during the pre-ovulatory and luteal phases where estrogen achieved its higher level might indicate a negative association that could explain 
the adiponectin variation during menstrual cycle in normal weight group.

The overweight/obese group showed an insignificant pattern of adiponectin variation during menstrual phases, this is in agreement to Rouen et al. (2010) who studied the influence of body mass index and the menstrual cycle on adipokines secretion where overweight subjects showed a relatively stable adiponectin level across the cycle (Rouen et al. 2010). In addition, lower adiponectin levels were recorded in overweight-obese group (BMI $\geq 25$ ) compared to normal weight group (BMI=18.5-24.99), confirming the strong negative correlation between serum adiponectin and adiposity indices (BMI, waist and hip circumferences), as has been mentioned in many previous studies (Gavrila et al. 2003, Hoffstedt et al. 2004, Jurimae and Jurimae 2007b). This could explain the absence of adiponectin variation in overweight/obese group due to the negative effect of adipose tissue on circulating adiponectin.

Our findings of no correlation between adiponectin and estradiol during menstrual phases are in line with many previous studies (Kleiblova et al. 2006, Asimakopoulos et al. 2009, Dafopoulos et al. 2009, Hall et al. 2009, Chatzidimitriou et al. 2015). Moreover, serum adiponectin has been observed to be unchanged during menopause despite depleted estrogen. Further support has come from an in-vitro study, when estradiol administration to human fat cells did not affect adiponectin expression and secretion (Horenburg et al. 2008). However, the literature on the relationship between adiponectin and estradiol are very inconsistent. Serum adiponectin levels were found to be increased and decreased in postmenopausal compared to premenopausal women reflecting negative and positive correlation respectively. Unfortunately, administration of exogenous estrogen to postmenopausal women failed to confirm either presence or absence of correlation between adiponectin and estrogen, instead, it increases further contradiction when showed no effect (Sieminska et al. 2005, Chalvatzas et al. 2009), an increase (Chu et al. 2006), and a decrease (Kunnari et al. 2008) in plasma adiponectin levels. Interestingly, serum adiponectin levels were unchanged in mice either post-ovariectomy or after estradiol treatment despite significant changes in adiponectin mRNA levels in perigonadal fat brought by these two interventions (Gui et al. 2004).

Although The reason for these discrepancies is not clear, it could be explained by the presences of many potential confounders in the existing studies that precluded a firm assessment of the relationship between adiponectin and estradiol, such as age (Koh et al. 2008), BMI (Hoffstedt et al. 2004), physical activity (Khoo et al. 2015), and food consumption (Izadi and Azadbakht 2015). However, we controlled the effect of BMI by the design of our study, an overnight fasting sampling had controlled the effect of food consumption, and all our subjects were in the same age group and with similar physical activity.

This contradiction in the results might highlight a complex multiloop mechanism controlling adiponectinestradiol relation instead of being simple unidirectional. Hence, the absence of correlation between adiponectin and estradiol doesn't mean an absence of adiponectin's role in female reproduction.

In conclusion, a significant variation of serum adiponectin level was detected across the menstrual cycle in females with normal weight. In comparison, overweight/obese group showed a relatively stable adiponectin level throughout the cycle. This lack of adiponectin variation might be added to the complex mechanisms lies behind obesity-related female infertility. Future researches on adiponectin effect on menstrual cycle physiology in females is needed, particularly comparisons between normal regular menstruating women and women with menstrual irregularities.

\section{Conflict of Interest}

There is no conflict of interest.

\section{Acknowledgements}

This work was supported by Deanship of Scientific Research - Imam Abdulrahman Bin Faisal University [grant number 2014293].

\section{References}

ASIMAKOPOULOS B, MILOUSIS A, GIOKA T, KABOUROMITI G, GIANISSLIS G, TROUSSA A, SIMOPOULOU M, KATERGARI S, TRIPSIANIS G, NIKOLETTOS N: Serum pattern of circulating adipokines throughout the physiological menstrual cycle. Endocr J 56: 425-433, 2009. 
BALSAN GA, VIEIRA JL, OLIVEIRA AM, PORTAL VL: Relationship between adiponectin, obesity and insulin resistance. Rev Assoc Med Bras 61: 72-80, 2015.

BEST D, BHATTACHARYA S: Obesity and fertility. Horm Mol Biol Clin Investig 24: 5-10, 2015.

BLÜHER M, MANTZOROS CS: From leptin to other adipokines in health and disease: Facts and expectations at the beginning of the 21st century. Metabolism 64: 131-145, 2015.

BOTTNER A, KRATZSCH J, MULLER G, KAPELLEN TM, BLUHER S, KELLER E, BLUHER M, KIESS W: Gender differences of adiponectin levels develop during the progression of puberty and are related to serum androgen levels. J Clin Endocrinol Metab 89: 4053-4061, 2004.

CAMINOS JE, NOGUEIRAS R, GAYTAN F, PINEDA R, GONZALEZ CR, BARREIRO ML, CASTANO JP, MALAGON MM, PINILLA L, TOPPARI J, DIEGUEZ C, TENA-SEMPERE M: Novel expression and direct effects of adiponectin in the rat testis. Endocrinology 149: 3390-3402, 2008.

CHABROLLE C, TOSCA L, RAME C, LECOMTE P, ROYERE D, DUPONT J: Adiponectin increases insulin-like growth factor I-induced progesterone and estradiol secretion in human granulosa cells. Fertil Steril 92: 19881996, 2009.

CHALVATZAS N, DAFOPOULOS K, KOSMAS G, KALLITSARIS A, POURNARAS S, MESSINIS IE: Effect of ovarian hormones on serum adiponectin and resistin concentrations. Fertil Steril 91: 1189-1194, 2009.

CHATZIDIMITRIOU K, GOUGOURA SG, BARGIOTA A, KOUKOULIS GN. Normal menstrual cycle steroid hormones variation does not affect the blood levels of total adiponectin and its multimer forms. J Clin Transl Endocrinol 2: 61-65, 2015.

CHENG XB, WEN JP, YANG J, YANG Y, NING G, LI XY: GnRH secretion is inhibited by adiponectin through activation of AMP-activated protein kinase and extracellular signal-regulated kinase. Endocrine 39: 6-12, 2011.

CHU MC, COSPER P, NAKHUDA GS, LOBO RA: A comparison of oral and transdermal short-term estrogen therapy in postmenopausal women with metabolic syndrome. Fertil Steril 86: 1669-1675, 2006.

COMBS TP, MARLISS EB: Adiponectin signaling in the liver. Rev Endocr Metab Disord 15: 137-147, 2014.

COMNINOS AN, JAYASENA CN, DHILLO WS: The relationship between gut and adipose hormones, and reproduction. Human Reproduction Update 20: 153-174, 2014.

DAFOPOULOS K, SOURLAS D, KALLITSARIS A, POURNARAS S, MESSINIS IE: Blood ghrelin, resistin, and adiponectin concentrations during the normal menstrual cycle. Fertil Steril 92: 1389-1394, 2009.

GAVRILA A, CHAN JL, YIANNAKOURIS N, KONTOGIANNI M, MILLER LC, ORLOVA C, MANTZOROS CS: Serum adiponectin levels are inversely associated with overall and central fat distribution but are not directly regulated by acute fasting or leptin administration in humans: cross-sectional and interventional studies. $J$ Clin Endocrinol Metab 88: 4823-4831, 2003.

GUI Y, SILHA JV, MURPHY LJ: Sexual dimorphism and regulation of resistin, adiponectin, and leptin expression in the mouse. Obes Res 12: 1481-1491, 2004.

HALL N, WHITE C, O'SULLIVAN AJ: The relationship between adiponectin, progesterone, and temperature across the menstrual cycle. J Endocrinol Invest 32: 279-283, 2009.

HOFFSTEDT J, ARVIDSSON E, SJOLIN E, WAHLEN K, ARNER P: Adipose tissue adiponectin production and adiponectin serum concentration in human obesity and insulin resistance. J Clin Endocrinol Metab 89: 13911396, 2004.

HORENBURG S, FISCHER-POSOVSZKY P, DEBATIN KM, WABITSCH MP: Influence of sex hormones on adiponectin expression in human adipocytes. Horm Metab Res 40: 779-786, 2008.

IZADI V, AZADBAKHT L: Specific dietary patterns and concentrations of adiponectin. J Res Med Sci 20: 178-184, 2015.

JURIMAE J, JURIMAE T: Adiponectin is a predictor of bone mineral density in middle-aged premenopausal women. Osteoporos Int 18: 1253-1259, 2007a.

JURIMAE J, JURIMAE T: Plasma adiponectin concentration in healthy pre- and postmenopausal women: relationship with body composition, bone mineral, and metabolic variables. Am J Physiol Endocrinol Metab 293: E42-47, $2007 b$. 
KAWWASS JF, SUMMER R, KALLEN CB: Direct effects of leptin and adiponectin on peripheral reproductive tissues: a critical review. Mol Hum Reprod 21: 617-632, 2015.

KHOO J, DHAMODARAN S, CHEN DD, YAP SY, CHEN RY, TIAN RH: Exercise-induced weight loss is more effective than dieting for improving adipokine profile, insulin resistance, and inflammation in obese men. Int $J$ Sport Nutr Exerc Metab 25: 566-575, 2015.

KLEIBLOVA P, SPRINGER D, HALUZIK M: The influence of hormonal changes during menstrual cycle on serum adiponectin concentrations in healthy women. Physiol Res 55: 661-666, 2006.

KOH SJ, HYUN YJ, CHOI SY, CHAE JS, KIM JY, PARK S, AHN CM, JANG Y, LEE JH: Influence of age and visceral fat area on plasma adiponectin concentrations in women with normal glucose tolerance. Clin Chim Acta 389: 45-50, 2008.

KUNNARI A, SANTANIEMI M, JOKELA M, KARJALAINEN AH, HEIKKINEN J, UKKOLA O, KESANIEMI YA: Estrogen replacement therapy decreases plasma adiponectin but not resistin in postmenopausal women. Metabolism 57: 1509-1515, 2008.

LANFRANCO F, ZITZMANN M, SIMONI M, NIESCHLAG E: Serum adiponectin levels in hypogonadal males: influence of testosterone replacement therapy. Clin Endocrinol (Oxf) 60: 500-507, 2004.

LATIF R, RAFIQUE N: Serum kisspeptin levels across different phases of the menstrual cycle and their correlation with serum oestradiol. Neth J Med 73: 175-178, 2015.

LU M, TANG Q, OLEFSKY JM, MELLON PL, WEBSTER NJ: Adiponectin activates adenosine monophosphateactivated protein kinase and decreases luteinizing hormone secretion in LbetaT2 gonadotropes. Mol Endocrinol 22: 760-771, 2008.

MAEDA K, OKUBO K, SHIMOMURA I, FUNAHASHI T, MATSUZAWA Y, MATSUBARA K: cDNA cloning and expression of a novel adipose specific collagen-like factor, apM1 (AdiPose Most abundant Gene transcript 1). Biochem Biophys Res Commun 221: 286-289, 1996.

MEMISH ZA, EL BCHERAOUI C, TUFFAHA M, ROBINSON M, DAOUD F, JABER S: Obesity and associated factors - Kingdom of Saudi Arabia, 2013. Preventing Chronic Disease 11: E174, 2014.

MICHALAKIS K, MINTZIORI G, KAPRARA A, TARLATZIS BC, GOULIS DG: The complex interaction between obesity, metabolic syndrome and reproductive axis: a narrative review. Metabolism 62: 457-478, 2013.

NGUYEN DM, EL-SERAG HB: The Epidemiology of Obesity. Gastroenterol Clin North Am 39: 1-7, 2010.

ROUEN PA, LUKACS JL, REAME NE: Adipokine concentrations in non obese women: a study of reproductive aging, body mass index, and menstrual cycle effects. Biol Res Nurs 12: 54-61, 2010.

SAXENA AR, SEELY EW, GOLDFINE AB: Cardiovascular risk factors and menstrual cycle phase in pre-menopausal women. J Endocrinol Invest 35: 715-719, 2012.

SCHERER PE, WILLIAMS S, FOGLIANO M, BALDINI G, LODISH HF: A novel serum protein similar to C1q, produced exclusively in adipocytes. $J$ Biol Chem 270: 26746-26749, 1995.

SIEMINSKA L, WOJCIECHOWSKA C, NIEDZIOLKA D, MAREK B, KOS-KUDLA B, KAJDANIUK D, NOWAK M: Effect of postmenopause and hormone replacement therapy on serum adiponectin levels. Metabolism 54: 1610-1614, 2005.

SRAMKOVA M, DUSKOVA M, VITKU J, VCELAK J, MATUCHA P, BRADNOVA O, DE CORDEIRO J, STARKA L: Levels of adipokines and some steroids during the menstrual cycle. Physiol Res 64 (Suppl 2): S147-S154, 2015.

TAMAKOSHI K, YATSUYA H, WADA K, MATSUSHITA K, OTSUKA R, YANG PO, SUGIURA K, HOTTA Y, MITSUHASHI H, TAKEFUJI S, KONDO T, TOYOSHIMA H: The transition to menopause reinforces adiponectin production and its contribution to improvement of insulin-resistant state. Clin Endocrinol (Oxf) 66: 65-71, 2007.

WEN JP, LV WS, YANG J, NIE AF, CHENG XB, YANG Y, GE Y, LI XY, NING G: Globular adiponectin inhibits GnRH secretion from GT1-7 hypothalamic GnRH neurons by induction of hyperpolarization of membrane potential. Biochem Biophys Res Commun 371: 756-761, 2008. 